\title{
ВЛИЯНИЕ ФИЛЬТРАЦИОННО-ЕМКОСТНЫХ СВОЙСТВ ПРИЗАБОЙНОЙ ЗОНЫ ПЛАСТА НА ЭФФЕКТИВНОСТЬ КИСЛОТНОЙ ОБРАБОТКИ
}

\author{
Дорфман Михаил Борисович1, \\ m.dorfman@narfu.ru \\ Сентемов Андрей Алексеевич1, \\ sentemov.a.a@yandex.ru \\ 1 Северный (Арктический) федеральный университет им. М.В. Ломоносова, \\ Россия, 163002, г. Архангельск, набережная Северной Двины, 17.
}

\begin{abstract}
Актуальность. В настоящее время больщой объем исследований по оптимизации интенсификации работы скважин связан с изучением влияния скорости закачки кислотных составов на характер образования каналов и определение оптимальных объемов закачки. Важным фактором является первоначальное состояние призабойной зоны скважины: первичная проницаемость; характер насыщения паста пластовыми фллюидами; объем внедрения и степень загрязнения буровой жидкостью.

Цель: оценка влияния начальных фрильтрационных характеристик призабойной зоны скважины на эффрективность солянокислотной обработки.

Методы. Были проведены опыты моделирующие соляно-кислотную обработку. Были использованы образцы с различными коллекторскими свойствами. В ряде экспериментов моделировалось загрязнение образиов буровым раствором.

Результаты. Эфффективность кислотной обработки образцов низкопроницаемой породы выше, чем в опытах с высокопроницаемыми кернами. В низкопроницаемых образцах сквозные каналы образуются при прокачке большего количества поровых объёмов кислотного раствора, чем в высокопроницаемых. Это связанно с тем, что раствор преимущественно расходуется на формирование новых каналов. Низкопроницаемые образцы имеют большую эквивалентную площадь образовавшихся каналов, что подтверждает большую эфффрективность кислотной обработки низкопроницаемых кернов. При снижении проницаемости коллектора вследствие загрязнения буровой жидкостью воздействие кислотного раствора происходит аналогично воздействию на незагрязнённый низкопроницаемый коллектор. Полученные результаты могут быть использованы при соляно-кислотной обработке на промысле с высокой вероятностью положительного эфффекта. В дальнейшем необходимо дать экономическую оценку с учётом времени прорыва кислоты и необходимого количества соляной кислоты.
\end{abstract}

\section{Ключевые слова:}

Соляно-кислотная обработка, число Дамкеллера, пористость, проницаемость, скорость реакции, керн.

\section{Введение}

Главный процесс, протекающий при солянокислотной обработке (СКО) скважин, - растворение кислотой карбонатных пород коллектора. Кислотный состав, проникая в поровые каналы, расширяет их, образуя узкие длинные каверны. После СКО продукты реакции относительно легко удаляются из призабойной зоны пласта (ПЗС) при вызове притока, так как они растворимы в воде. Задача СКО - увеличение проницаемости системы каналов и микротрещин в ПЗС. Это приводит к увеличению дебита или приемистости скважины.

В настоящее время многие исследования, проводимые с целью оптимизации операций по интенсификации работы скважины, направлены на изучение кинетики реакции соляно-кислотных составов с карбонатными породами. Эти исследования связанны с изучением влияния скорости закачки кислотных составов, характера образования каналов, определение оптимальных объемов закачки и других параметров [1-11].

Стоит отметить, что существенное значение на эффективность соляно-кислотной обработки оказывает первоначальное состояние призабойной зоны пласта: первичная проницаемость; характер насыщения пласта пластовыми флюидами; объем внедрения и степень загрязнения буровой жидкостью. С целью определить влияние первоначальных фильтрацион- ных характеристик ПЗС на эффективность СКО был проведён ряд экспериментов по воздействию кислотным раствором на карбонатный керн.

\section{Экспериментальная часть}

Эксперименты проводили на установке постоянного расхода, переоборудованной для работы с соляно-кислотными растворами. Применялись контейнеры и манифольд, изготовленные из нержавеющей стали. Для фиксации колебаний давления при фильтрации жидкостей применялся самопишущий манометр. Для замеров объёма жидкостей, прошедших через образец, а также для предотвращения выбросов кислоты применялась автоматическая бюретка. Давление гидрообжима поддерживалось 10-20 МПа.

Всего было проведено шесть опытов по вытеснению пластовых флюидов из образцов известняка (карбонатность 80-100%). В опытах № 1 и 2 первоначально моделировалось загрязнение ПЗС буровым раствором на основе $0,15 \%$ раствора полиакриламида (ПАА). После чего на керн воздействовали солянокислотным раствором. В опытах № 3 и 5 воздействовали на высокопроницаемые образцы, насыщенные моделями пластовой воды и нефти соответственно. В опытах № 4 и 6 аналогичное воздействие производили на низкопроницаемые образцы керна.

В качестве модели пластовой воды использовали раствор $\mathrm{NaCl}$ плотностью 1100 кг/м³ (опыты № 1, 3, 4). 
В качестве модели нефти - керосин плотностью 796 кг/м³ и вязкостью 1,24 мПа*с (опыты № 2, 5, 6).

Все флюиды прокачивались в одном направлении. В связи с малыми размерами образцов керна изменение проницаемости в таких образцах незначительно зависит от направления фильтрации. Поэтому изменение направления фильтрации не окажет существенного влияния на результаты. План эксперимента представлен в табл. 1.

Таблица 1. Дизайн эксперимента

Table 1. Design of the experiment

\begin{tabular}{|c|c|c|c|c|c|c|}
\hline $\begin{array}{c}\text { № oпыта } \\
\text { experiment no. }\end{array}$ & 1 & 2 & 3 & 4 & 5 & 6 \\
\hline \begin{tabular}{|l|} 
Коэффициент \\
пористости \\
Porosity
\end{tabular} & 0,08 & 0,09 & 0,09 & 0,07 & 0,010 & 0,06 \\
\hline $\begin{array}{l}\text { Коэффициент } \\
\text { проницаемости, } \\
\text { мкм }^{2} \\
\text { Permeability, } \mu \mathrm{m}^{2} \\
\end{array}$ & 0,07 & 0,28 & 1,5 & 0,2 & 1,62 & 0,15 \\
\hline \begin{tabular}{|l} 
Модель насыща- \\
ющего флюида \\
Saturating fluid \\
model
\end{tabular} & $\begin{array}{l}\text { вода } \\
\text { water }\end{array}$ & $\begin{array}{c}\text { нефть } \\
\text { oil }\end{array}$ & $\begin{array}{c}\text { вода } \\
\text { water }\end{array}$ & $\begin{array}{l}\text { вода } \\
\text { water }\end{array}$ & $\begin{array}{c}\text { нефть } \\
\text { oil }\end{array}$ & $\begin{array}{c}\text { нефть } \\
\text { oil }\end{array}$ \\
\hline \begin{tabular}{|l|} 
Образец загряз- \\
нён моделью \\
бурового раствора \\
Sample contami- \\
nated with mud \\
model \\
\end{tabular} & + & + & - & - & - & - \\
\hline $\begin{array}{l}\text { Тип образца } \\
\text { керна } \\
\text { Type of core } \\
\text { sample }\end{array}$ & - & - & 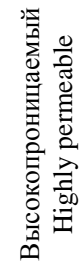 & 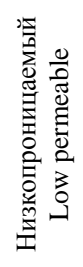 & 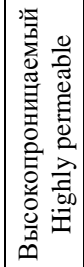 & 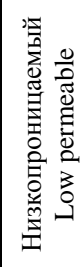 \\
\hline
\end{tabular}

В опытах № 1 и 2 первоначально определяли гидродинамическую подвижность насыщающего керн раствора при покачивании через образец с постоянной скоростью 1-3 поровых объемов пластовой жидкости до стабилизации. После чего прокачивали не менее 3 поровых объемов модели бурового раствора. Во всех опытах поддерживали постоянную скорость фильтрации, расход жидкости составлял 0,135 $\mathrm{cm}^{3} /$ мин. На следующей стадии подключали к кернодержателю контейнер с $12 \%$ соляной кислотой и прокачивали кислоту при том же расходе до прорыва кислоты через образец и полного падения перепада давления на образце. Расход закачки кислоты подбирался таким образом, чтобы градиент давления не превышал градиент давления гидроразрыва. Во всех опытах фиксировали перепад давления с помощью образцовых манометров. Объем прокаченной жидкости определяли с помощью автоматической бюретки. По полученным данным, согласно закону Дарси, определяли гидродинамическую подвижность $(\mathrm{k} / \mu)$ фильтрующихся через образец жидкостей.

В опытах № 3, 5 использовали высокопроницаемые образцы керна. Первоначально прокачивали модель пластовой воды и модель нефти соответственно. Далее проводили воздействие кислотным раствором и проводили прокачку первоначальной жидкостью. Опыты № 4, 6 проводили аналогично опытам № 3, 5, только с использованием низкопроницаемых образцов керна. Результаты опытов приведены на рис. 1-4.

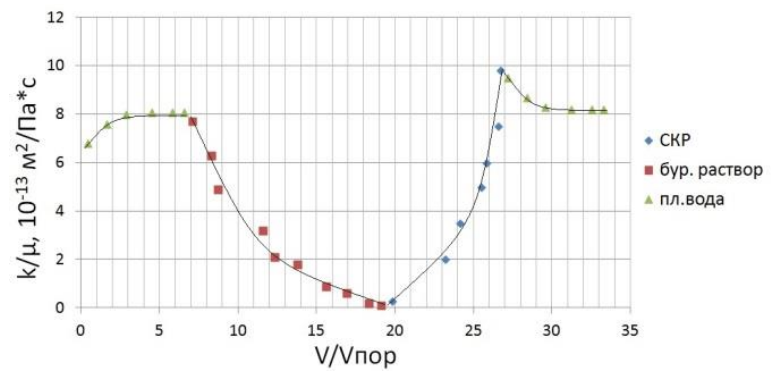

Рис. 1. Зависимость подвижности при фильтрации модели бурового раствора, пластовой воды и соляно-кислотного раствора (опьт № 1)

Fig. 1. Dependence of hydrodynamic mobility in filtration model of the drilling fluid, produced water and hydrochloric acid solution (experiment no. 1)

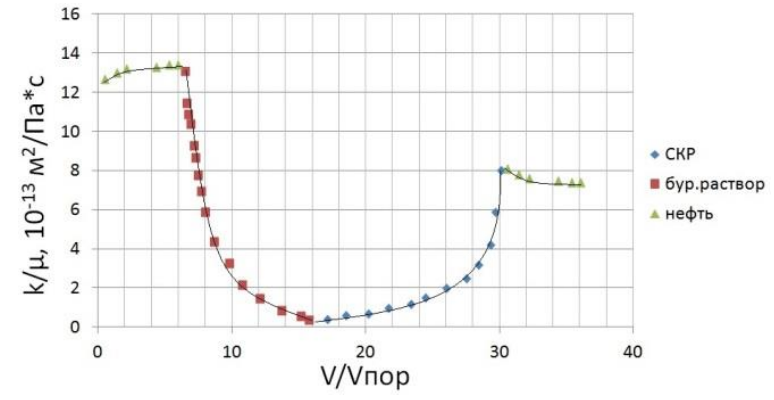

Pис. 2. Зависимость подвижности при фильтрации модели бурового раствора, нефти и солянокислотного раствора (опыт № 2)

Fig. 2. Dependence of hydrodynamic mobility in filtration model of the drilling fluid, oil and hydrochloric acid solution (experiment no. 2)

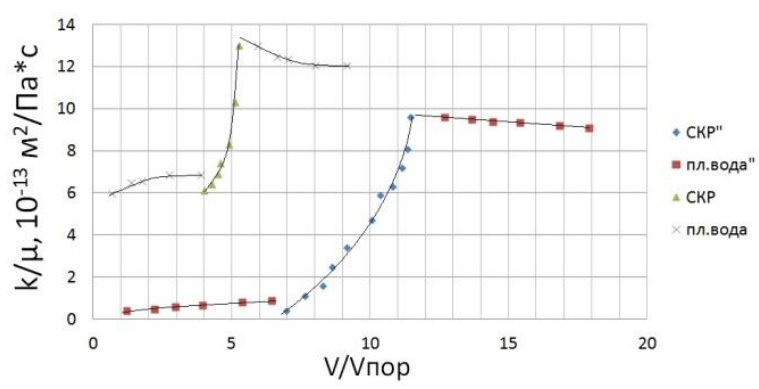

Рис. 3. Зависимость подвижности при фильтраџии модели пластовой воды и соляно-кислотного раствора (без шттиха высокопроницаемьй образеи, опыт № 3; со штрихом низкопроницаемый образеи, опыт № 4)

Fig. 3. Dependence of hydrodynamic mobility when filtering a model of produced water and hydrochloric acid solution (without a stroke, a highly permeable sample, experiment no. 3; with a stroke, a lowpermeability sample, experiment no. 4)

При покачивании через образец модели бурового раствора гидродинамическая подвижность снижается более чем в 10 раз по сравнению с начальной, что 
объясняется адсорбцией пористой средой молекул полимера и уменьшением сечения каналов фильтрации, а также образованием в процессе фильтрации гелеобразного уплотняющего слоя ПАА на входном торце образца.

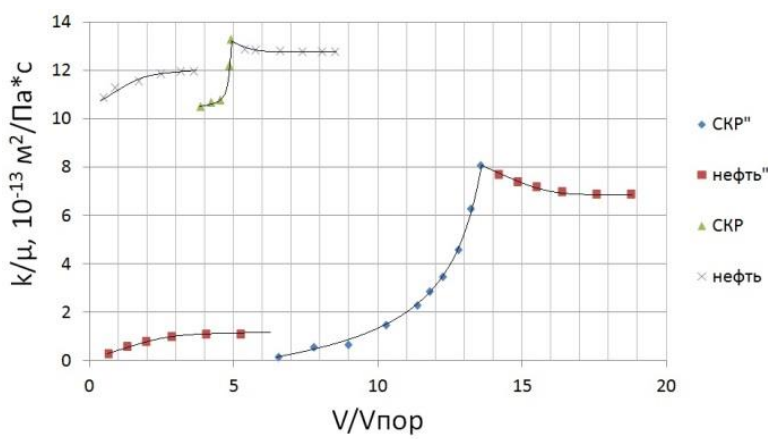

Рис. 4. Зависимость подвижности при фильтраџии модели нефти и соляно-кислотного раствора (без штриха высокопроницаемый образец, опыт № 5; со итрихом низкопронииаемый образеи, onbim № 6)

Fig. 4. Dependence of hydrodynamic mobility when filtering a model of oil and hydrochloric acid solution (without a stroke, a highly permeable sample, experiment no. 5; with a stroke, a low-permeability sample, experiment no. 6)

Такое снижение подвижности моделирует временную изоляцию пласта при загрязнении буровым раствором. Восстановление и увеличение проницаемости керна проводили $12 \%$ раствором соляной кислоты. Как видно из рис. 1-4, при прокачке кислоты гидродинамическая подвижность постепенно увеличивалась и через некоторое время резко возрастала за счёт образовавшегося одного или нескольких сквозных каналов растворения. Причем, судя по форме линий, процесс взаимодействия кислоты с образцами, насыщенными моделями пластовой воды и нефти, различался. На рис. 1 крутой начальный подъем графика гидродинамической подвижности при закачке кислоты объясняется малым взаимным растворением кислотного и бурового составов. А на рис. 2 более пологий начальный подъем линии, вероятно, соответствует пробковому вытеснению двух не смешивающихся жидкостей.

\section{Результаты и их обсуждение}

По результатам экспериментов проведена оценка эффективности восстановления подвижности после обработки соляно-кислотным раствором. Как видно из рис. 5 , степень возрастания подвижности тем выше, чем ниже первоначальная проницаемость, независимо от того, был ли это естественный низкопроницаемый керн или ухудшение коллекторских свойств произошло вследствие воздействия бурового раствора.

Отмечается также, что в водонасыщенном керне эффект роста подвижности выше по сравнению с нефтенасыщенным, что объясняется различным характером смачиваемости.

Эффективность кислотного воздействия оценивается и по необходимому количеству прокачиваемых поровых объёмов кислотного раствора для создания каналов. Впервые на это было обращено внимание в работах $[10,11]$. По результатам проведённых опытов получено, что с ростом проницаемости относительное количество кислотного раствора, необходимое для создания сквозных каналов, снижается (рис. 6). Сравнение абсолютных объёмов показывает, что сохраняется тенденция зависимости объёмов соляно-кислотного раствора для образования сквозных каналов от проницаемости, как и для относительных объёмов (рис. 7).

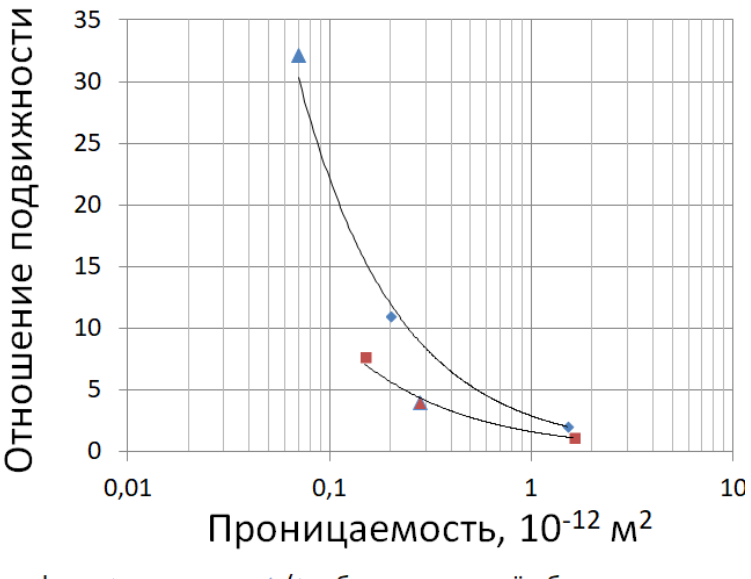

घ нефть • пл. вода $\Delta / \Delta$ образез загрязнён бур. раствором

Pис. 5. Зависимость падения подвижности при обработке кислотным раствором от проницаемости

Fig. 5. Dependence of hydrodynamic mobility decrease during acidizing on permeability

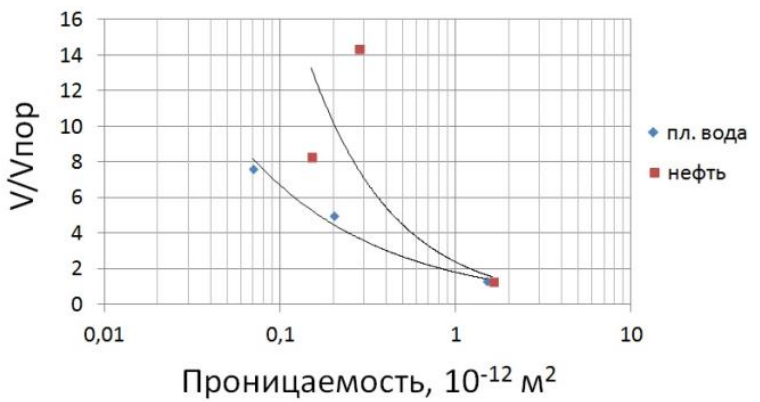

Pис. 6. Относительный объём кислотного раствора для образования сквозного канала

Fig. 6. Relative volume of acid solution for formation of a through channel

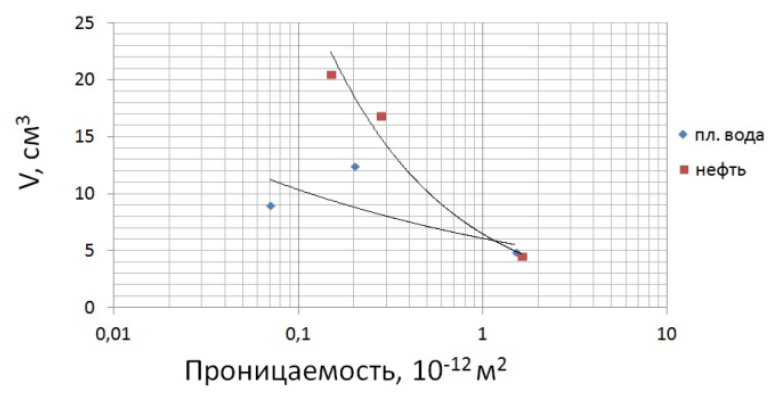

Рис. 7. Объём кислотного раствора для образования сквозного канала

Fig. 7. Volume of acidic solution for formation of a through channel 
В работах [10-12] установлена зависимость прокаченных объёмов (V/Vпор) от числа Дамкеллера, которое описывается уравнением (1):

$$
D a=\frac{S k}{Q},
$$

где $S$ - эквивалентная площадь сквозных каналов, см² ; $k$ - общая константа скорости реакции, см/мин; $Q-$ расход закачиваемой кислоты, $\mathrm{cm}^{3} /$ мин.

Для оценки эквивалентной площади сквозных каналов можно использовать зависимость объема прокачанного раствора кислоты до образования сквозного канала от обратного числа Дамкеллера, полученную экспериментально для подобных условий (рис. 8). Опыты, проведённые в ходе работы, происходили на режиме, относящемся к левой части графика $(1 / \mathrm{Da}<2,45)$. Правой же области $(1 / \mathrm{Da}>2,45)$ соответствуют режимы с относительно высокой скоростью подвода реагента, что в реальных условиях достигается при давлении, выше давления гидроразрыва [10].

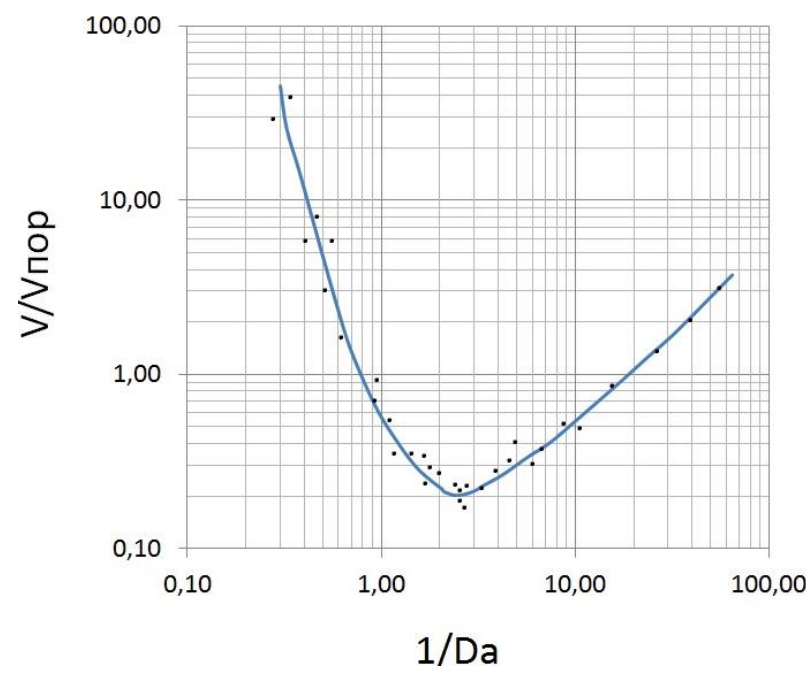

Pис. 8. Зависимость объема прокачанного раствора кислоты для прорыва на выходе из образиа от обратного числа Дамкеллера

Fig. 8. Dependence of acid solution volume for a breakthrough on the inverse Damkeller number

Таблица 2. Результаты обработки

Table 2. Processing results

\begin{tabular}{|c|c|c|c|c|c|c|}
\hline $\begin{array}{c}\text { № Опыта } \\
\text { Experiment no. }\end{array}$ & 1 & 2 & 3 & 4 & 5 & 6 \\
\hline V/Vпор/V/Vpor & 7,63 & 14,36 & 1,38 & 5,02 & 1,30 & 8,29 \\
\hline $1 / D a$ & 0,43 & 0,38 & 0,68 & 0,48 & 0,74 & 0,46 \\
\hline$D a$ & 2,33 & 2,63 & 1,4788 & 2,08 & 1,35 & 2,17 \\
\hline$S, \mathrm{~cm}^{2} / S, \mathrm{~cm}^{2}$ & 1,374 & 1,704 & 0,216 & 0,495 & 0,190 & 0,516 \\
\hline
\end{tabular}

\section{СПИСОК ЛИТЕРАТУРЫ}

1. Антонов С.М., Андреев О.В., Киселев К.В. Влияние гелирующих агентов на реологические и фильтрационные характеристики соляной кислоты // Известия вузов. Нефть и газ. 2014. - № 2. - C. 77-82.

2. Смирнов А.С., Федоров К.М., Шевелев А.П. О моделировании кислотного воздействия на карбонатный пласт // Известия РАН. Серия: МЖГ. - 2010. - № 5. - С. 114-121.

3. Солодовников А.О., Андреев О.В., Киселев К.В. Формирование червоточин кислотообразующими реагентами в модели
Исходя из объёма прокаченного кислотного раствора до образования сквозного канала по графику (рис. 8), были определены число Дамкеллера и эквивалентная площадь поровых каналов для каждого опыта. Результаты обработки приведены в табл. 2 и на рис. 9.

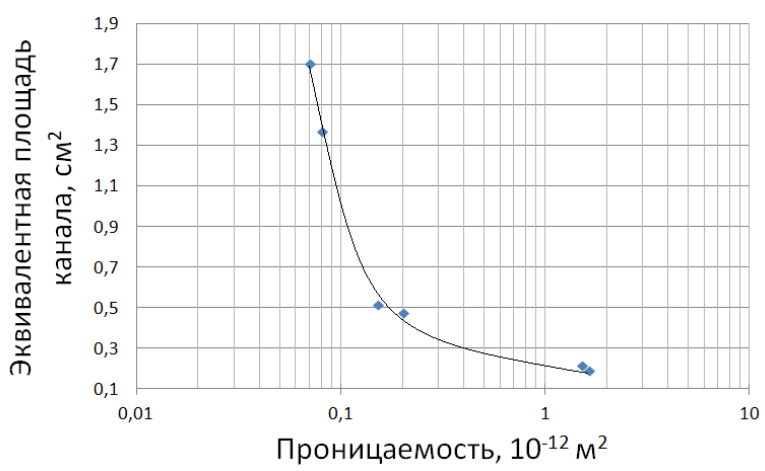

Puc. 9. Эквивалентная площадь сквозного канала в зависимости от первоначальной проницаемости

Fig. 9. Through channel equivalent area depending on initial permeability

Как видно из рис. 9, сквозные каналы, образующиеся при меньшей проницаемости, имеют большую эквивалентную площадь. Это связанно с тем, что существует корреляция между проницаемостью и радиусом поровых каналов. Радиус каналов высокопроницаемых образцов больше. Поэтому в высокопроницаемых коллекторах большая часть кислотного раствора затрачивается на расширение уже существующих поровых каналов, а образование новых происходит с меньшей эффективностью в сравнении с низкопроницаемыми коллекторами [13-20].

\section{Заключение}

При равных условиях коллекторские свойства образцов керна с низкой проницаемостью улучшились в большей степени в сравнении с высокопроницаемыми. При обработке низкопроницаемых коллекторов требуется относительно больший объём солянокислотного раствора. Это обусловлено тем, что объём кислоты преимущественно затрачивается на образование новых каналов, а не на расширение уже существующих. Эквивалентная площадь позволяет оценить эффективность образования новых сквозных каналов. У низкопроницаемых образцов эквивалентная площадь значительно выше, что подтверждает большую эффективность кислотной обработки низкопроницаемых кернов.

карбонатного пласта // Известия вузов. Нефть и газ. - 2012. № 6. - C. 59-63.

4. Солодовников А.О., Андреев О.В., Киселев К.В. Влияние скорости закачки растворов кислотообразующих реагентов на структуру каналов фильтрации // Башкирский химический журнал. - 2013. - № 1. - С. 135-137.

5. Andreev O.V., Antonov S.M., Kiselev K.V. Kinetics of reaction between gelled $\mathrm{HCl}$ and dolomite $\mathrm{Ca} 1,16 \mathrm{Mg} 0,84(\mathrm{CO} 3) 2$ and filtration of gelled acid in a reservoir core sample // International Journal of Oil, Gas and Coal Technology. - 2017. - V. 14. № 4. - P. 369-379. 
6. Van Hong L., Ben H. A preliminary screening and characterization of suitable acids for sandstone matrix acidizing technique: a comprehensive review Ministry of Higher Education // Journal of Petroleum Exploration and Production Technology. - 2019. V. 9 (1). - P. 753-778.

7. Rabbani E., Davarpanah A., Memariani M. An experimental study of acidizing operation performances on the wellbore productivity index enhancement // Journal of Petroleum Exploration and Production Technology. - 2018. - V. 8 (4). - P. 1243-1253.

8. Combination flooding technology used in high temperature, high salinity heavy oil reservoirs of Shengli oilfield / J. Shi, X. Cao, H. Wang, S. Guo, X. Xia // Special oil and gas reservoirs. 2018. - V. 25. - № 4. - P. 129-133.

9. Herianto M. Improving effective porosity of rocks with matrix acidizing stimulation on sand stone formation // The International Journal of Innovative Research and Development. - 2018. V. 7 (9). - P. 282-292.

10. Fredd C.N., Fogler H.S. Influence of transport and reaction on wormhole formation in porous media // American Institute of Chemical Engineers Journal. - 1998. - V. 44. - № 9. - P. 1933-1949.

11. Fredd C.N., Fogler H.S. The kinetics of calcite dissolution in acetic acid solutions // Chemical Engineering Science. - 1998. V. 53. - № 22. - P. 38-63.

12. Fredd C.N., Fogler H.S. Alternative stimulation fluids and their impact on carbonate acidizing // Society of Petroleum Engineers Journal. - 1998. - № 3. - P. 34-41.

13. Барковский Н.Н., Плотников В.В., Якимов О.И. Комплексные лабораторные исследования технологии кислотной обработки терригенного и карбонатного коллекторов, в том числе с применением самоотклоняющихся кислотных составов // Геология, геофизика и разработка нефтяных и газовых месторождений. -2016 . - № 7. - С. 36-43.
14. Гаджиев Г.К. Повышение эффективности обработки призабойной зоны пласта микроэмульсиями // Нефтепромысловое дело. - 2016. - № 2. - С. 33-35.

15. Андреев О.В., Антонов С.М., Киселев К.В. Взаимодействие вязких растворов $\mathrm{HCl}$ с кальцитом и доломитом в условиях высокой минерализации // Вестник Санкт-Петербургского государственного университета. - 2016. - Т. 3. - № 61. C. $321-330$.

16. Медведева Н.А., Уваров С.Г., Береговой А.Н., Амерханов М.И., Рахимова Ш.Р., Зиатдинова Р.Ш., Андриянова О.М., Лакомкин В.Н. Методика выбора кислотной композиции для проведения успешной обработки низкопроницаемых карбонатных и терригенных коллекторов // Оборудование и технологии для нефтегазового комплекса. - 2015. - № 5. - С. 21-24.

17. Мельникова Е.В., Нифантов В.И. Повышение эффективности освоения скважин на месторождениях Восточной Сибири // Территория нефтегаз. - 2015. - № 2. - С. 19-25.

18. Комплексный подход и опыт проведения кислотной обработки в сложных условиях карбонатных коллекторов ВолгоУральского региона / Р. Каюмов, А. Конченко, А. Клюбин, О. Леванюк, К. Бурдин, А. Чикин, Е. Никульшин // Время колтюбинга. - 2015. - № 1. - С. 24-39.

19. Phase Diagram of the Y-Y2Se3 system, enthalpies of phase transformations / O.V. Andreev, V.B. Kharitontsev, A.A. Polkovnikov et al. // Journal of Solid State Chemistry. - 2015. - V. 230. P. 186-190.

20. Совершенствование технологии кислотных обработок / А.А. Хакимов, Р.И. Сатаров, А.В. Качурин, А.В. Акимкин // Нефтяное хозяйство. - 2012. - № 3. - С. 53-54.

Поступила 24.01.2020 2.

\section{Информация об авторах}

Дорфман М.Б., кандидат технических наук, доцент кафедры бурения скважин, разработки нефтяных и газовых месторождений Северного (Арктического) федерального университета им. М.В. Ломоносова.

Сентемов $\boldsymbol{A}$. $\boldsymbol{A}$., аспирант кафедры бурения скважин, разработки нефтяных и газовых месторождений Северного (Арктического) федерального университета им. М.В. Ломоносова. 
UDC 622.276 .63

\title{
INFLUENCE OF RESERVOIR PROPERTIES OF THE BOTTOMHOLE ZONE ON ACIDIZING EFFICIENCY
}

\author{
Mikhail B. Dorfman', \\ m.dorfman@narfu.ru \\ Andrey A. Sentemov', \\ sentemov.a.a@yandex.ru \\ 1 Northern (Arctic) Federal University named after M.V. Lomonosov, \\ 17, Severnaya Dvina embankment, Arkhangelsk, 163002, Russia.
}

Relevance. Currently, a large amount of research is directed on optimization of well operation. It is associated with the study of the effect of injection rate of acidizing on the nature of formation of channels and determination of optimal injection volumes. One of the important factors is the initial state of the bottomhole zone: permeability, saturation of reservoir fluids, contaminate of the drilling fluid. The main aim of this work is to assess the effect of the initial filtration characteristics of the bottomhole zone on acidizing efficiency. Methods. Several experiments were performed simulating the acidizing. Samples with different reservoir properties were used. A number of experiments modeling contamination of samples with drilling mud were performed.

Results. It was found that under equal conditions the core samples with low permeability has better efficiency with acidizing in comparison with highly permeability cores. Larger amount of hydrochloric acid solution is required to create breakthrough channels in low-permeable reservoirs. The equivalent surface of the channels allows evaluating the effectiveness of acidizing. The equivalent surface of acid-formed channels is higher for the samples with low permeability. The effect of acidizing for cores contaminated with the drilling fluid and lowpermeable cores is equal. The results obtained can be used in acidizing in the field with a high probability of a positive effect. In the future, it is necessary to give an economic assessment, taking into account the time of formation of breakthrough channels and the required amount of $\mathrm{HCl}$ acid.

\section{Key words:}

Acidizing, Damkeller number, porosity, permeability, reaction rate, core sample.

\section{REFERENCES}

1. Antonov S. M., Andreev O. V., Kiselev K. V. Influence of gelling agents on filtration characteristics of hydrochloric acid. The journal «Oil and Gas Studies», 2014, no. 2, pp. 77-82. In Rus.

2. Smirnov A.S., Fedorov K.M., Shevelev A.P. O modelirovanii kislotnogo vozdeystviya na karbonatny plast [About modeling of acid effects on carbonate formation]. Fluid Dynamics, 2010, no. 5, pp. 114-121.

3. Solodovnikov A.O., Andreev O.V., Kiselev K.V. Generation of wormholes by acid-forming reagents in the carbonate reservoir model. Oil and Gas Studies, 2012, no. 6, pp. 59-63. In Rus.

4. Solodovnikov A.O., Andreev O.V., Kiselev K.V. Influence of pumping rate of acid forming reagents solutions on channel filtration structure. Bashkir Chemical Journal, 2013, no. 1, pp. 135-137. In Rus.

5. Andreev O.V., Antonov S.M., Kiselev K.V. Kinetics of reaction between gelled $\mathrm{HCl}$ and dolomite $\mathrm{Ca} 1,16 \mathrm{Mg} 0,84(\mathrm{CO} 3) 2$ and filtration of gelled acid in a reservoir core sample. International Journal of Oil, Gas and Coal Technology, 2017, vol. 14, no. 4, pp. 369-379.

6. Hong L. Van, Ben H. A preliminary screening and characterization of suitable acids for sandstone matrix acidizing technique : a comprehensive review Ministry of Higher Education. Journal of Petroleum Exploration and Production Technology, 2019, vol. 9 (1), pp. 753-778.

7. Rabbani E., Davarpanah A., Memariani M. An experimental study of acidizing operation performances on the wellbore productivity index enhancement. Journal of Petroleum Exploration and Production Technology, 2018, vol. 8 (4), pp. 1243-1253.

8. Shi J., Cao X., Wang H., Guo S., Xia X. Combination flooding technology used in high temperature, high salinity heavy oil reservoirs of Shengli oilfield. Special oil and gas reservoirs, 2018, vol. 25 , no. 4, pp. 129-133.

9. Herianto M. Improving effective porosity of rocks with matrix acidizing stimulation on sand stone formation. The International Journal of Innovative Research and Development, 2018, vol. 7 (9), pp. 282-292.

10. Fredd C.N., Fogler H.S. Influence of transport and reaction on wormhole formation in porous media. American Institute of Chemical Engineers Journal, 1998, vol. 44, no. 9, pp. 1933-1949.
11. Fredd C.N., Fogler H.S. The kinetics of calcite dissolution in acetic acid solutions. Chemical Engineering Science, 1998, vol. 53, no. 22 , pp. 38-63.

12. Fredd C.N., Fogler H.S. Alternative stimulation fluids and their impact on carbonate acidizing. Society of Petroleum Engineers Journal, 1998, no. 3, pp. 34-41.

13. Barkovsky N.N., Plotnikov V.V., Yakimov O.I. Komleksnye laboratornye issledovaniya tekhnologii kislotnoy obrabotki terrigennogo i karbonatnogo kollektorov, $\mathrm{v}$ tom chisle s primeneniem samootklonyayushchikhsya kislotnykh sostavov [Integrated laboratory studies of the technology of acid treatment of terrigenous and carbonate reservoirs, including using self-diverting acid formulations]. Geologiya, geofizika i razrabotka neftyanykh i gazovykh mestorozhdeniy, 2016, no. 7, pp. 36-43.

14. Gadzhiev G.K. Povyshenie effektivnosti obrabotki prizaboynoy zony plasta mikroemulsiyami [Improving the efficiency of the bottomhole formation zone treatment with microemulsions]. Neftepromyslovoe delo, 2016, no. 2, pp. 33-35.

15. Andreev O.V. The interaction of viscous solutions of $\mathrm{HCl}$ with calcite and dolomite in conditions of high mineralization. Vestnik of Saint-Petersburg University, 2016, vol. 3, no. 61, pp. 321-330. In Rus.

16. Medvedeva N.A., Uvarov S.G., Beregovoy A.N., Amerkhanov M.I., Rakhimova S.R., Ziatdinova R.S., Andriyanova O.M., Lakomkin V.N. Metodika vybora kislotnoy kompozitsii dlya provedeniya uspeshnoy obrabotki nizkopronitsaemykh karbonatnykh i terrigennykh kollektorov [Method for selecting an acid composition for successful treatment of low-permeable carbonate and terrigenous reservoirs]. Oborudovanie i tekhnologii dlya neftegazovogo kompleksa, 2015, no. 5, pp. 21-24.

17. Melnikova E.V., Nifantov V.I. Efficiency increase of well development at Eastern Siberia deposits. Oil and Gas Territory, 2015, no. 2, pp. 19-25. In Rus.

18. Kayumov R., Konchenko A., Klyubin A., Levanyuk O., Burdin K., Chikin A., Nikulshin E. An integrated approach and the experience of acidizing in the challenging Environment of carbonate reservoirs of the Volga-Ural region. Coiled Tubing Times, 2015, no. 1, pp. 24-39. In Rus. 
19. Andreev O.V., Kharitontsev V.B., Polkovnikov A.A. Phase diagram of the Y-Y2Se3 system, enthalpies of phase transformations. Journal of Solid State Chemistry, 2015, vol. 230, pp. 186-190.
20. Khakimov A.A., Satarov R.I., Kachurin A.V., Akimkin A.V. Acid treatment technological advancement. Oil Industry, 2012, no. 3, pp. 53-54. In Rus.

Received: 24 January 2020.

\section{Information about the authors}

Mikhail B. Dorfman, Cand. Sc., associate professor, Northern (Arctic) Federal University named after M.V. Lomonosov. Andrey A. Sentemov, postgraduate student, Northern (Arctic) Federal University named after M.V. Lomonosov. 